Marquette University

e-Publications@Marquette

9-2014

\title{
Multi-Objective Tradeoffs in the Design Optimization of a Brushless Permanent-Magnet Machine With Fractional-Slot Concentrated Windings
}

\author{
Peng Zhang \\ Marquette University \\ Gennadi Y. Sizov \\ Marquette University \\ Muyang Li \\ Marquette University \\ Dan M. Ionel \\ University of Wisconsin - Milwaukee \\ Nabeel Demerdash \\ Marquette University, nabeel.demerdash@marquette.edu
}

See next page for additional authors

Follow this and additional works at: https://epublications.marquette.edu/electric_fac

Part of the Computer Engineering Commons, and the Electrical and Computer Engineering Commons

\section{Recommended Citation}

Zhang, Peng; Sizov, Gennadi Y.; Li, Muyang; Ionel, Dan M.; Demerdash, Nabeel; Stretz, Steven J.; and Yeadon, Alan W., "Multi-Objective Tradeoffs in the Design Optimization of a Brushless Permanent-Magnet Machine With Fractional-Slot Concentrated Windings" (2014). Electrical and Computer Engineering Faculty Research and Publications. 205.

https://epublications.marquette.edu/electric_fac/205 


\section{Authors}

Peng Zhang, Gennadi Y. Sizov, Muyang Li, Dan M. Ionel, Nabeel Demerdash, Steven J. Stretz, and Alan W. Yeadon 
Marquette University

e-Publications@Marquette

\section{Electrical and Computer Engineering Faculty Research and Publications/College of Engineering}

This paper is NOT THE PUBLISHED VERSION.

Access the published version at the link in the citation below.

IEEE Transactions on Industry Applications, Vol. 50, No. 5 (September-October 2014): 3285-3294. DOI. This article is (C) The Institute of Electrical and Electronics Engineers and permission has been granted for this version to appear in e-Publications@Marquette. The Institute of Electrical and Electronics Engineers does not grant permission for this article to be further copied/distributed or hosted elsewhere without the express permission from The Institute of Electrical and Electronics Engineers.

\section{Multi-Objective Tradeoffs in the Design Optimization of a Brushless Permanent- Magnet Machine with Fractional-Slot Concentrated Windings}

Peng Zhang Department of Electrical and Computer Engineering, Marquette University, Milwaukee, WI Gennadi Y. Sizov Department of Electrical and Computer Engineering, Marquette University, Milwaukee, WI Muyang Li Department of Electrical and Computer Engineering, Marquette University, Milwaukee, WI Dan M. Ionel Regal Beloit Corporation, Beloit, WI Nabeel A. O. Demerdash 
Department of Electrical and Computer Engineering, Marquette University, Milwaukee, WI

Steven J. Stretz

Regal Beloit Corporation, Beloit, WI

Alan W. Yeadon

Regal Beloit Corporation, Beloit, WI

\begin{abstract}
:
In this paper, a robust parametric model of a brushless permanent magnet machine with fractional-slot concentrated windings, which was developed for automated design optimization is presented. A computationally efficient finite-element analysis method was employed to estimate the dq-axes inductances, the induced voltage and torque ripple waveforms, and losses of the machine. A method for minimum effort calculation of the torque angle corresponding to the maximum torque per ampere load condition was developed. A differential evolution algorithm was implemented for the global design optimization with two concurrent objectives of minimum losses and minimum material cost. An engineering decision process based on the Pareto-optimal front for 3,500 candidate designs is presented together with discussions on the tradeoffs between cost and performance. One optimal design was finally selected, prototyped and successfully tested.
\end{abstract}

\title{
SECTION I. Introduction
}

THE latest developments in computer hardware and software technologies enabled substantial research work on automated design optimization of electric machines using stochastic methods such as genetic algorithms, particle swarm, simulated annealing, and differential evolution (DE), e.g., [1]- [2] [3] [4] [5] [6]. Among these algorithms, DE has been shown to outperform other population based evolutionary techniques on most bench mark test functions [7]. In one of the earliest applications to electric machines, the DE algorithm was compared to eight other stochastic search algorithms for identifying the parameters of induction machines [8]. From this investigation, the authors concluded that DE was robust, easy to tune, fast, accurate and simple to implement. In a more recent benchmark study for permanent-magnet (PM) synchronous machines, the relative merits of DE algorithms in comparison with the widely known technique of response surface-design of numerical experiments were illustrated [1].

Recently, a computationally efficient electromagnetic finite-element analysis (CE-FEA) technique has been introduced and coupled to large-scale design optimization procedures [9]- [10] [11]. Previous publications have proven the satisfactory accuracy of the CE-FEA method [10]- [11] [12] [13]. The backemf and induced voltage waveforms, ripple and average torque, as well as stator core losses can be calculated systematically using the CE-FEA technique [10], [11]. In such machines, the PM eddy-current losses can be computed using a hybrid method combining the CE-FEA approach with a novel analytical formulation [12]. The skew effects are directly accounted for in the harmonic domain according to the CE-FEA method [13].

This paper brings further new contributions to the CE-FEA method, including minimum-effort calculation methods for the PM flux linkage, dq-axes inductances, torque angle for the maximum 
torque per ampere (MTPA) load condition, together with further insights on the stator core losses. A new robust parametric CE-FEA model for a 12-slot 10-pole concentrated winding interior permanentmagnet (IPM) topology for a brushless (BL) machine driven by a sine-wave current regulated power electronic drive is introduced and optimized.

In terms of new electric machine optimization techniques, losses and material cost were set-up as concurrent objectives and employed in conjunction with three constraints for torque ripple, total harmonic distortion (THD) of the induced voltage waveform, and the minimum operating point in the PMs. The problem was solved through DE within the new general framework depicted in Fig. 1. An engineering decision procedure was established based on a Pareto-set of optimal designs and a tradeoff study leading to the selection of a recommended design. Finally, the design has been prototyped and tested, and the results used for model validation and calibration.

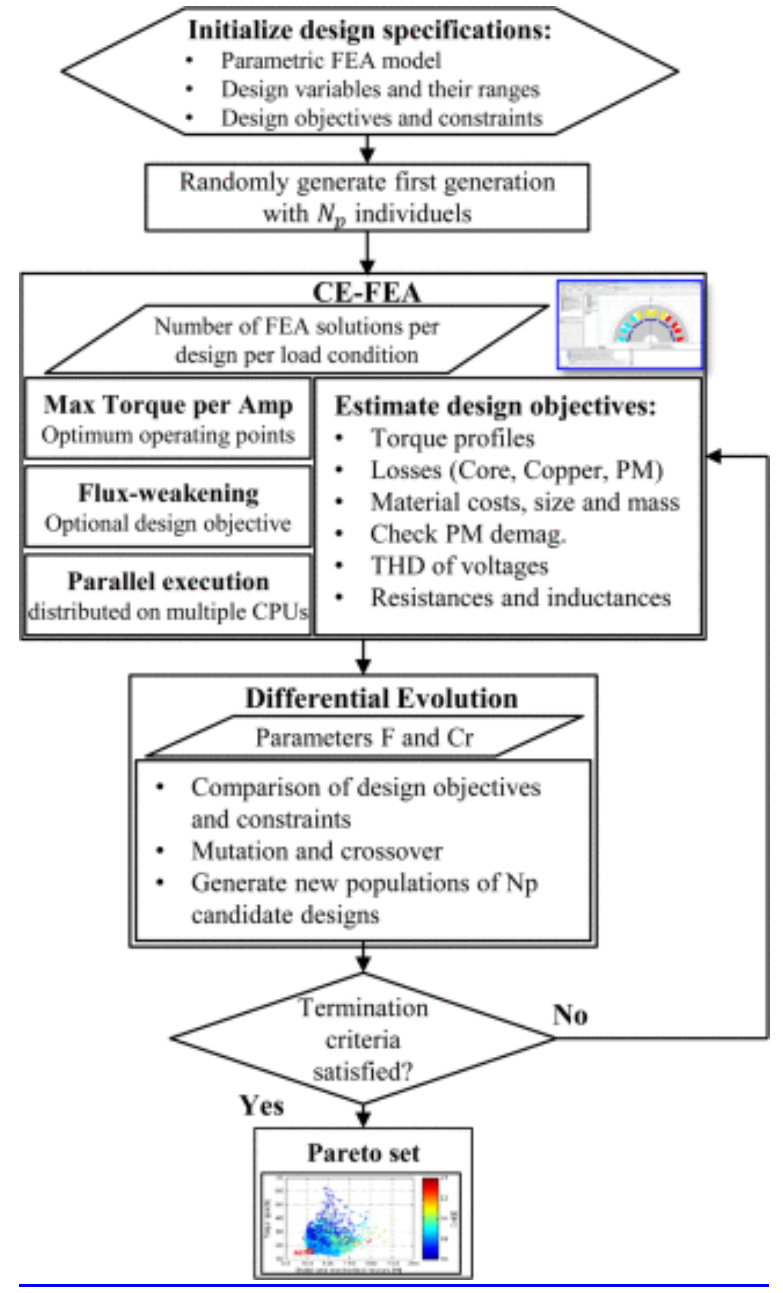

Fig. 1. Flowchart of the automated design optimization utilizing the computationally efficient-FEA (CE-FEA) and differential evolution (DE) algorithm.

\section{SECTION II. Parametric Modeling of a PM Machine}

In this paper, a case-study of a 12-slot 10-pole BLPM machine, with a V-type layout of PMs in the rotor and a standard NEMA 210-frame, was parameterized and design optimized with the rated condition of 
$10 \mathrm{hp}$ at $1800 \mathrm{r} / \mathrm{min}$. The detailed parametric model is shown in Fig. 2 with a zoom-in for the PM component and its parameters given in Fig. 3.

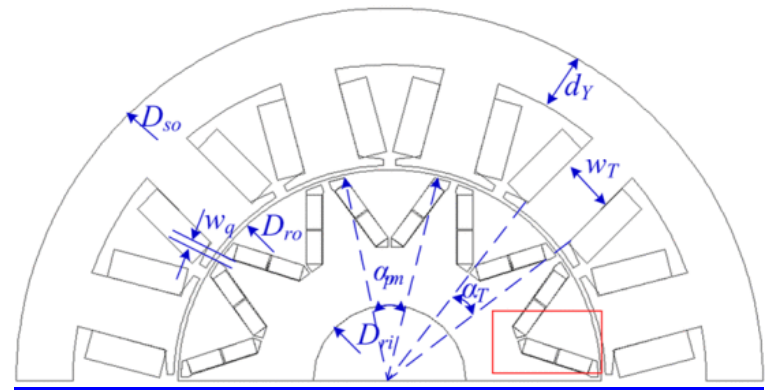

Fig. 2. Parametric model of a 12-slot 10-pole BLPM machine.

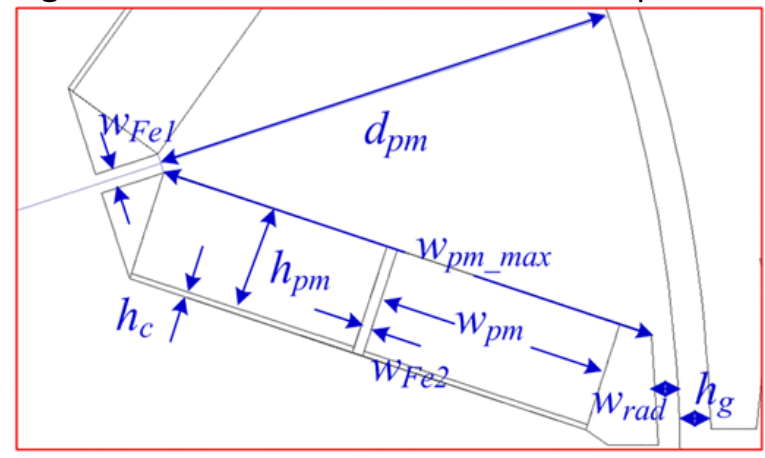

Fig. 3. Zoom in of the red rectangle in Fig. 2.

In order to avoid the geometric conflicts in the automated design optimization procedure, design variables such as the stator inner diameter, $D_{s i}$, tooth width, $w_{T}$, PM width, $w_{p m}$, and PM depth, $d_{p m}$, were defined using ratio expressions of $k_{s i}, k_{w T}, k_{w p m}$, and $k_{d p m}$, respectively, as also given in Table I. Here, $k_{s i}$ is the split ratio between the stator inner diameter and outer diameter, and $k_{w T}$ is the ratio between the tooth arc angle, $\alpha_{T}$, and the slot pitch angle, $\alpha_{s}=2 \pi / N_{s}$, while, $N_{s}$ is the number of stator slots. In the ratio expression of $k_{w p m}$, the maximum width of two magnets, $w_{p m \_m a x}$, can be decided by the magnet depth, $d_{p m}$, and the pole arc angle, $\alpha_{p m}$. In the design optimization, several geometric variables were fixed, such as the stator outer diameter, $D_{s o}$, rotor inner diameter, $D_{r i}$, the distances between PM segments, $w_{F e 1}$ and $w_{F e 2}$, Figs. 2 and 3, and the distance from the PM top flux barrier to the rotor outer diameter, wrad. Based on these definitions and assumptions, the selected geometric variables for the DE design optimization are $\left[k_{s i}, h_{g}, k_{w T}, d_{Y}, h_{p m}, k_{w p m}, k_{d p m}, w_{q}, \alpha_{p m}\right]$, with the corresponding variable ranges provided in Table I.

TABLE I Definition and Ranges of Nine Design Variables Depicted in Figs. 2 and 3

\begin{tabular}{|c|l|l|l|}
\hline Design variables & Definition & Min & Max \\
\hline$k_{s i}$ & $D_{s i} / D_{s o}$ & 0.5 & 0.7 \\
\hline$h_{g}$ & airgap height & $0.7 \mathrm{~mm}$ & $1.3 \mathrm{~mm}$ \\
\hline$k_{w T}$ & $\alpha_{T} / \alpha_{s}$ & 0.35 & 0.55 \\
\hline$d_{Y}$ & yoke thickness & $13.0 \mathrm{~mm}$ & $20.0 \mathrm{~mm}$ \\
\hline$h_{p m}$ & PM height & $2.5 \mathrm{~mm}$ & $5.0 \mathrm{~mm}$ \\
\hline$k_{w p m}$ & $2 w_{p m} / w_{p m \_ \text {max }}$ & 0.65 & 0.95 \\
\hline$k_{d p m}$ & $2 d_{p m} /\left(D_{r o}-D_{r i}\right)$ & 0.15 & 0.65 \\
\hline
\end{tabular}




\begin{tabular}{|c|l|l|l|}
\hline$w_{q}$ & q-axis bridge width & $0.5 \mathrm{~mm}$ & $4.0 \mathrm{~mm}$ \\
\hline$\alpha_{p m}$ & pole arc [elec. deg.] & 95 & 130 \\
\hline
\end{tabular}

In the manufacturing process, the slot of the magnet is always wider and thicker than the actual PM physical cross-sectional dimensions, as shown by the clearances under the PMs in Fig. 3. Here, the clearance under the PM, $h_{c}$, is aligned in series along the flux path in the magnetic circuit. This renders it having significant effects on the performance estimation in the FEA, which will lead to 2-3\% difference in the open circuit back-emf estimation. Thus, when parameterizing the model, the clearance must be taken into account.

\section{SECTION III. Performance Estimation Using CE-FEA}

Unlike the time-stepping FEA (TS-FEA), CE-FEA only employs the minimum number of static field solutions such as in [9], [10]. Based on the pole-pitch and slot-pitch symmetry and periodicity property of the electromagnetic field in BLPM machines, the three phase flux linkages and flux density distributions in the stator core and PMs can be constructed using space-time transformation [9], [10], [12]. As a consequence, the back-emfs/induced voltages and torque profiles, stator core losses and PM eddy-current losses were calculated as presented in [10], [12]. In this section, the computation methods for the PM flux linkage, dq-axes inductances and the torque angle for the MTPA load condition are described separately. Meanwhile, the improved core loss coefficients' model [14]- [15] [16] was integrated into the CE-FEA method to obtain a better estimate of the stator core losses.

\section{A. PM Flux Linkage and dq-Axes Inductances}

In the design optimization of BLPM machines, all the designs are assumed to be simulated under the MTPA load condition. Thus, in order to compute the correct torque angle for such a rated load condition, the PM flux linkage and dq-axes inductances are prerequisites. The method to compute these three parameters utilizes Park's transformation, $\underline{T}_{s}$, as defined in the following expression:

$$
T_{S}=\frac{2}{3}\left[\begin{array}{ccc}
\cos (\theta) & \cos \left(\theta-\frac{2 \pi}{3}\right) & \cos \left(\theta-\frac{4 \pi}{3}\right) \\
-\sin (\theta) & -\sin \left(\theta-\frac{2 \pi}{3}\right) & -\sin \left(\theta-\frac{4 \pi}{3}\right) \\
\frac{1}{2} & \frac{1}{2} & \frac{1}{2}
\end{array}\right]
$$

where $\theta=\theta_{0}+\omega t$, and $\theta_{0}$ is the initial rotor position, while $\omega$ is the electrical angular speed.

The well-known dq-frame formulation in the phasor form can be expressed as follows:

$$
\bar{V}=\omega \bar{\lambda}_{p m}+R_{s} \bar{I}+j X_{d} \bar{I}_{d}+j X_{q} \bar{I}_{q}
$$


where $\bar{V}$ and $\bar{I}$ are the terminal phase voltage and current phasors, respectively, and $\bar{\lambda}_{p m}$ is the PM flux linkage pasor, while $R_{S}$ is the phase resistance. Here, the subscripts $d$ and $q$ represent the $d$ - and $q$ axes components, and $X$ stands for the reactance, $X=\omega L$, while $L$ is the inductance. This relationship is also shown in the dq-phasor diagram of such PM machines in Fig. 4. Here, the phase angle between the current phasor and the $d$-axis is defined as the torque angle, $\beta$. The phase angle between the voltage phasor and current phasor is the power factor angle, $\varphi$.

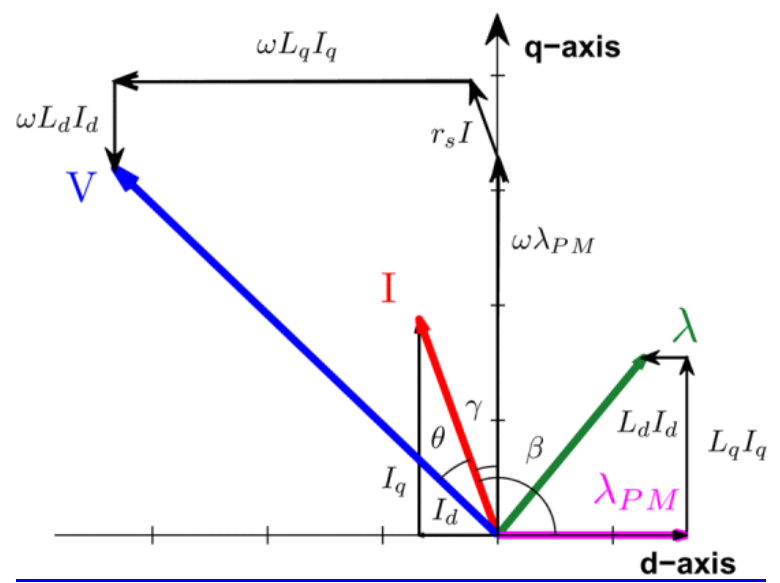

Fig. 4. Phasor diagram for PM synchronous machines.

From Park's transformation, the well-known dq-frame formulation of flux linkages is given in the following expression:

$$
\left\{\begin{array}{c}
\lambda_{d}=\lambda_{p m}+L_{d} i_{d} \\
\lambda_{q}=L_{q} i_{q} .
\end{array}\right.
$$

The detailed procedure to utilize expression (2) and Park's transformation is described in the following steps.

1. With the simulation model running at $90{ }^{\circ} \mathrm{e}$ ( oe: electrical degree) torque angle and rated sinewave current, one can obtain FEA solutions for a sufficient number of rotor positions. From these solutions, the three phase flux linkages can be obtained from the FEA results. Under this load condition, the $d$-axis current is equal to zero. Thus, the PM flux linkage can be calculated as follows:

$$
\begin{aligned}
\lambda_{p m}=\lambda_{d}= & \frac{2}{3}\left[\cos (\theta) \lambda_{a}+\cos (\theta-2 \pi / 3) \lambda_{b}\right. \\
& \left.+\cos (\theta-4 \pi / 3) \lambda_{c}\right] .
\end{aligned}
$$

2. Simulate the FEA model under a load condition with a typical value of the torque angle between $100{ }^{\circ} \mathrm{e}$ and $120^{\circ} \mathrm{e}$, and rated sinewave current, another set of three phase flux linkages, $\underline{\lambda}_{a b c}$, and currents, $\underline{i}_{a b c}$, can be obtained. After the application of the dq- 
transformation, the real time values of the dq-reference frame flux linkages, $\underline{\lambda}_{d q 0}$, and currents, $\underline{i}_{d q 0}$, can be expressed as follows:

$$
\left\{\begin{array}{l}
\underline{\lambda}_{d q 0}=\underline{T}_{s} \underline{\lambda}_{a b c} \\
\underline{i}_{d q 0}=\underline{T}_{s} \underline{i}_{a b c} .
\end{array}\right.
$$

(4)

3. From the dq-frame formulation, the $d$-axis and q-axis inductances can hence be computed using the following expressions:

$$
\left\{\begin{array}{c}
L_{d}=\left(\lambda_{d}-\lambda_{p m}\right) / i_{d} \\
L_{q}=\lambda_{q} / i_{q} .
\end{array}\right.
$$

(5)

This approach is advantageous, as it considers for the PM flux linkage and dq-inductance calculation, the magnetic saturation substantially corresponding to the rated operation, including self-axis and cross-coupling effects due to armature reaction. Furthermore, the technique is faster as it requires solving only two FEA models for on-load operation at different torque angles, as opposed to three models for conventional approaches that calculate the PM flux linkage from an open-circuit simulation and the dq-inductance from models excited with currents in the $d$ and $q$ axis, respectively. Finally, the procedure is advantageous in terms of implementation practicality, being given the specifics of the scripting software developed, which employs a commercially available FEA solver [17].

\section{B. Torque Angle for the MTPA Load Condition}

Here, the electromagnetic torque, $T_{e}$, developed by the PM machine can be expressed as follows:

$$
T_{e}=\frac{3}{2} \frac{P}{2}\left(\lambda_{d} i_{q}-\lambda_{q} i_{d}\right)
$$

where $P$ is the number of poles. Substituting $(2)$ in the above expression, the electromagnetic torque can be re-expressed as follows:

$$
T_{e}=\frac{3}{2} \frac{P}{2}\left(\lambda_{p m} i_{q}+\left(L_{d}-L_{q}\right) i_{d} i_{q}\right)
$$

This torque expression identifies two torque components: 1$)$ the magnetic (alignment/synchronous) torque component $\left[(3 / 2)(P / 2) \lambda_{p m} i_{q}\right]$, and 2$)$ the reluctance torque component $\left[(3 / 2)(P / 2)\left(L_{d}-\right.\right.$ $\left.L_{q}\right) i_{d} i_{q}$. In a surface-mounted permanent magnet (SPM) machine, the reluctance torque is very small or negligible due to the almost equal magnitudes of the d-axis inductance, $L_{d}$, and q-axis inductance, $L_{q}$. One should notice that in an IPM machine, $L_{q}>L_{d}$, unlike a wound-field, salient-pole, synchronous machine or an SPM machine. 
Substituting for $i_{d}=I \cos (\beta)$ and $i_{q}=I \sin (\beta)$ into expression (7), the electromagnetic torque formula can be rewritten as follows:

$$
T_{e}=\frac{3}{2} \frac{P}{2}\left(\lambda_{p m} \operatorname{Isin}(\beta)+\left(L_{d}-L_{q}\right) I^{2} \sin (\beta) \cos (\beta)\right) .
$$

Equating the derivative of the electromagnetic torque expression

$$
\frac{d T_{e}}{d \beta}=\frac{3 P}{4}\left[\lambda_{p m} \operatorname{I} \cos (\beta)+\left(L_{d}-L_{q}\right) I^{2}\left(2 \cos ^{2}(\beta)-1\right)\right]
$$

to zero, under the assumption of constant parameters, i.e., inductances and flux linkage, yields the angle, $\beta$, that provides the maximum electromagnetic torque per amp (MTPA)

$$
\beta=\arccos \left(\frac{-\lambda_{p m} I+\sqrt{\lambda_{p m}^{2} I^{2}+8\left(L_{d}-L_{q}\right)^{2} I^{4}}}{4\left(L_{d}-L_{q}\right) I^{2}}\right) .
$$

This approach provides a fast estimation, which employed in combination with parameters calculated from nonlinear FEA, as previously described, typically yields satisfactory results. For reference, in the study from this paper, the typical current density was $4 \mathrm{~A} / \mathrm{mm}^{2}$ and flux density in the tooth was $1.7 \mathrm{~T}$.

\section{Core Loss Computation Method}

In the CE-FEA method, the excess loss is neglected, and the CAL2 model given in [14] can be used to estimate the core loss coefficients $k_{h}(f, B)$ and $k_{e}(f, B)$, which are used in the following specific core loss $(\mathrm{W} / \mathrm{kg}$ or $\mathrm{W} / \mathrm{lb})$ calculation model:

$$
w_{F e}=k_{h}(f, B) f B^{2}+k_{e}(f, B)(f B)^{2}
$$

where the hysteresis loss coefficient, $k_{h}$, and eddy-current loss coefficient, $k_{e}$, are functions of the peak flux density, $B$, and the frequency, $f$.

Previously obtained results demonstrated that within frequency ranges, the $k_{h}$ and $k_{e}$ coefficients can be considered as functions of the flux density only [15], [16], [18]. Thus, the third-order polynomials for these two coefficients with the lowest relative error values, as validated in [15], [16], [18], was utilized in the CE-FEA method, which are given as follows: 


$$
\left\{\begin{array}{l}
k_{h}(B)=k_{h 3} B^{3}+k_{h 2} B^{2}+k_{h 1} B+k_{h 0} \\
k_{e}(B)=k_{e 3} B^{3}+k_{e 2} B^{2}+k_{e 1} B+k_{e 0}
\end{array}\right.
$$

Based on the specific core loss coefficients and constructed flux densities [10] in the stator teeth and yoke, the total stator core losses can be computed according to the following steps:

1. The specific hysteresis harmonic losses and eddy-current losses in the stator teeth and yoke are calculated as follows:

$$
\begin{aligned}
& w_{h}=\sum_{\substack{n=1 \\
n_{\max }}}^{n_{\max }} k_{h}\left(B_{n}\right)\left(n f_{1}\right) B_{n}^{2} \\
& w_{e}=\sum_{n=1}^{k_{e}\left(B_{n}\right)\left(n f_{1}\right)^{2} B_{n}^{2}}
\end{aligned}
$$

(13)(14)

where $n$ is the harmonic order, and $B_{n}$ is the amplitude of the flux density for the $n$th harmonic, while $f_{1}$ is the fundamental frequency.

2. The total core losses in the stator can be calculated as follows:

$$
P_{F e S}=\left(w_{h T}+w_{e T}\right) m_{T}+\left(w_{h Y}+w_{e Y}\right) m_{Y}
$$

where $m_{T}$ and $m_{Y}$ are the masses of the stator teeth and yoke, respectively.

\section{SECTION IV. Design Optimization Using DE}

In the automated design optimization, a DE algorithm was utilized to generate a set of candidate designs, which were analyzed with the CE-FEA method to estimate the torque profile, induced voltage waveforms, and the losses in the stator core, copper as well as PMs [9], [10], [12], [13]. Material costs were also calculated. All the simulations were performed on an HP Z800 workstation with 12 cores (2 Xeon X5690 processors) and 32 GB RAM memory. Parallel execution for the CE-FEA technique was implemented in order to fully utilize the multiple CPUs and the "distributed solve" functions available within the ANSYS Maxwell software [17]. Overall, this resulted in a substantial increase of the computational speed in comparison to the well-known time-consuming TS-FEA.

The DE algorithm aims to find a global minimum or maximum by iteratively improving a population of candidate designs until the stopping criterion is satisfied. The principles of DE optimization and its application to electrical machine problems were previously introduced in [11], [19]. In the case of single-objective problems, the evolution and the "goodness" of the optimized design can be evaluated through simple comparison to other designs. In case of multi-objective problems with multiple 
constraints, where conflicts may exist between objectives, the stopping criteria and the decisionmaking based on a Pareto-front are more complicated [20], [21].

Within the DE algorithm, through mutation and crossover procedures, a trial generation of designs is produced. This trial generation is then compared to the current generation, in order to select the newnext generation. The Lampinen's criterion [7] was implemented to evaluate the two objectives and three constraints for the designs from the current and trial generations. In summary, a trial design is selected for the new generation if:

- it satisfies all constraints and has a lower or equal objective value than the design from the current generation, or

- it satisfies all constraints, while the current design does not, or

- $\quad$ neither the trial nor the current designs satisfy the constraints, however, the trial design does not violate any constraint more than the current design.

Major advantages of Lampinen's method are that constraints can be implemented without having to empirically determine penalty weights for multi-objective functions, and that no additional control parameters need to be set-up by the user. The constraints are influencing the design optimization evolution at the selection stage for the next generation based on the current and a trial generation. Finally, after completing the optimization process the designs with unsatisfied constraints were eliminated from the Pareto-front.

\section{A. Problem Statement}

A multi-objective design optimization for this BLPM machine requires the DE algorithm to search for designs in order to:

- $\quad$ minimize losses: $P_{\text {loss }}=P_{\mathrm{Cu}}+P_{\mathrm{Fe}_{-} \text {stator }}+P_{\mathrm{pm}}+P_{m e}$;

- $\quad$ minimize the material cost: Cost $=140 m_{p m}+8 m_{C u}+1 m_{F e}$;

where $P_{C u}, P_{F e}, P_{p m}$, and $P_{f w}$ are the copper losses, stator core losses, magnet losses, and mechanical losses, respectively, while $m_{p m}, m_{C u}$, and $m_{F e}$ are the masses of the PM, copper and steel materials, respectively. In the cost function, the specific cost of steel is set-up as the base (unity) value for all materials.

Three design constraints are required and defined by the following expressions:

- $\quad$ torque ripple under the rated load condition, $\left(\max \left(T_{e}\right)-\min \left(T_{e}\right)\right) /\left(\operatorname{average}\left(T_{e}\right)\right) \leq 5 \%$;

- total harmonic distortion (THD) in the induced voltage waveform under the rated load condition $\leq 3 \%$; and

- $\quad$ minimum flux density in PMs under the rated load condition, $B_{\min } \geq 0.3 B_{r}$, where, for the PM material used here the retentivity, $B_{r}=1.1 T$.

In the design optimization procedure, the operating temperature in the windings and PMs for all the candidate designs was assumed to be $100{ }^{\circ} \mathrm{C}$. Meanwhile, all the candidate designs have the same slot 
fill factor and current density, which led in each case to different ampere-turns due to the changed net slot areas. For each candidate design, the stack length was scaled to obtain a shaft torque of $42 \mathrm{Nm}$, which corresponds to $10.6 \mathrm{hp}$ output power rating at $1800 \mathrm{r} / \mathrm{min}$.

\section{B. Design Optimization Results}

Based on the previously introduced design specifications, the optimization of this BLPM machine was performed utilizing the DE algorithm coupled with the electromagnetic CE-FEA method. There were 70 individual designs per generation and 50 generations, which yielded a total of 3,500 design candidates. The results of the optimization study shown in Fig. 5 were directly calculated with CE-FEA and do not include the rotor core losses, which would have required a time consuming time-stepping FEA (TSFEA). With CE-FEA, the advantages in terms of computational savings are significant, making possible the completion of the optimization study in only 28 hours on a state of the art PC workstation.

For the Pareto-optimal front, defined as the collection of results for which an improvement of one objective can only be achieved through the deterioration of another objective, three candidate designs were selected and labeled as $M-1, M-2$, and $M-3$. Design $M-1$ represents a high efficiency solution, and motor M-3 has lower cost, while machine M-2 is a compromise alternative. In Fig. 5 the base value for losses corresponds to a maximum specification of $406 \mathrm{~W}$ and the base cost corresponds to design $\mathrm{M}-1$. The cross sections of these three PM machines are shown in Fig. 6, and the corresponding geometric variables and the weights are presented in Table II.

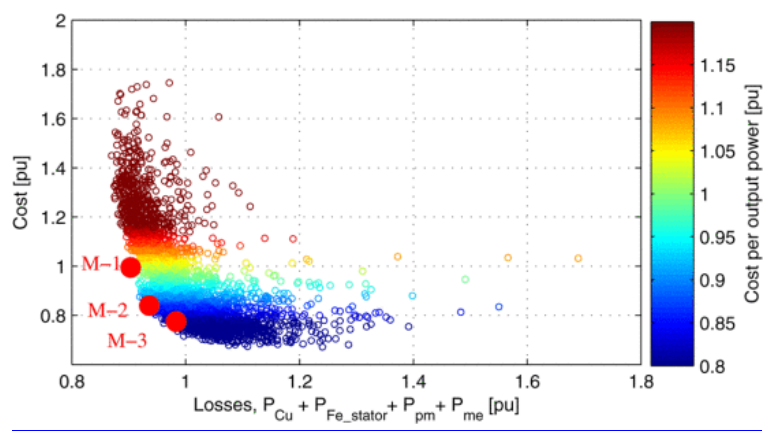

Fig. 5. Scattered plot for 3,500 candidate designs ( $50 \mathrm{DE}$ generations, each with 70 individuals) analyzed with electromagnetic CE-FEA. Three recommended designs $\mathrm{M}-1, \mathrm{M}-2$, and $\mathrm{M}-3$, are identified on the Pareto-front.

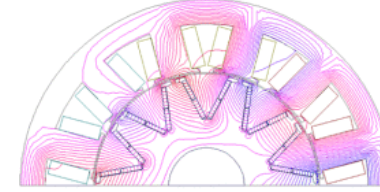

(a) (b)

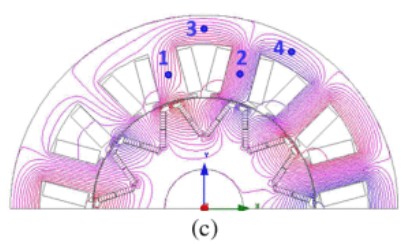

Fig. 6. Cross sections and flux plots of three recommended 12-slot 10-pole designs from the Pareto-front shown in Fig. 5. (a) M-1; (b) M-2; (c) M-3.

TABLE II Relative Values for the Geometric Variables. Machine M-3 was Selected as the Reference for the Other Selected Designs 


\begin{tabular}{|l|l|l|l|}
\hline Geometric variables & $\mathrm{M}-1$ & $\mathrm{M}-2$ & $\mathrm{M}-3$ \\
\hline Axial stack length & 1.23 & 1 & 1 \\
\hline Stator inner diameter, $D_{s i}$ & 1.06 & 0.99 & 1 \\
\hline Airgap height, $h_{g}$ & 1.82 & 1.12 & 1 \\
\hline Tooth width, $w_{T}$ & 1.12 & 1.05 & 1 \\
\hline Stator back iron thickness, $d_{Y}$ & 0.94 & 0.97 & 1 \\
\hline PM thickness, $h_{p m}$ & 0.90 & 0.88 & 1 \\
\hline PM width, $w_{p m}$ & 1.22 & 1.29 & 1 \\
\hline PM depth, $d_{p m}$ & 1.28 & 1.40 & 1 \\
\hline Q-axis bridge width, $w_{q}$ & 1.24 & 1.08 & 1 \\
\hline Pole arc, $\alpha_{p}$ & 0.92 & 1.04 & 1 \\
\hline Weights & & & \\
\hline PM & 1.35 & 1.14 & 1 \\
\hline Steel & 1.24 & 1.03 & 1 \\
\hline Copper & 1.09 & 0.93 & 1 \\
\hline
\end{tabular}

TABLE III Performance of the Recommended Motor Designs From Fig. 5

\begin{tabular}{|l|l|l|l|l|}
\hline Performance & Units & $\mathrm{M}-1$ & $\mathrm{M}-2$ & $\mathrm{M}-3$ \\
\hline Saliency ratio & & 1.17 & 1.24 & 1.29 \\
\hline Torque angle & {$[\mathrm{deg}]$.} & 96 & 97 & 99 \\
\hline Electromagnetic torque & {$[\mathrm{Nm}]$} & 42.31 & 42.83 & 42.87 \\
\hline Electromagnetic power & {$[\mathrm{W}]$} & 7975 & 8073 & 8081 \\
\hline Copper loss & {$[\mathrm{W}]$} & 145 & 124 & 133 \\
\hline Input power & {$[\mathrm{W}]$} & 8120 & 8197 & 8214 \\
\hline PM loss & {$[\mathrm{W}]$} & 18 & 20 & 16 \\
\hline Rotor core loss & {$[\mathrm{W}]$} & 53 & 60 & 41 \\
\hline Stator core loss & {$[\mathrm{W}]$} & 113 & 146 & 158 \\
\hline Total core loss & {$[\mathrm{W}]$} & 166 & 206 & 199 \\
\hline Mechanical loss & {$[\mathrm{W}]$} & 91 & 91 & 91 \\
\hline Total loss & {$[\mathrm{W}]$} & 420 & 440 & 439 \\
\hline Output power & {$[\mathrm{W}]$} & 7700 & 7757 & 7775 \\
\hline Shaft torque & {$[\mathrm{Nm}]$} & 41.69 & 41.62 & 41.65 \\
\hline Efficiency & {$[\%]$} & 94.83 & 94.63 & 94.65 \\
\hline Material cost & {$[\mathrm{pu}]$} & 1.00 & 0.84 & 0.78 \\
\hline
\end{tabular}

SECTION V. Comparison Between Candidate Designs and Optimal Tradeoff Studies

For the optimally designed $M-1, M-2$, and $M-3$ motors, the performance characteristics at rated power and rated speed of $1800 \mathrm{r} / \mathrm{min}$ are summarized in Table III, and, unlike Fig. 5, include the rotor core losses obtained from TS-FEA simulations. Despite the 12-slot 10-pole combination, the PM losses are relatively low due to the deep V-rotor configuration and PM circumferential segmentation, meaning that in the cross-section there are 4 magnet blocks per pole. 
In industrial applications, the motors operate in a range of variable torque and speed, and in order to provide a more systematic comparison for the three candidate designs, the so-called efficiency maps have been calculated and are shown in Fig. 7(a)-(c). On these efficiency maps, the black solid curve corresponds to a typical fan/pump load for the given $10 \mathrm{hp}$ power rating.
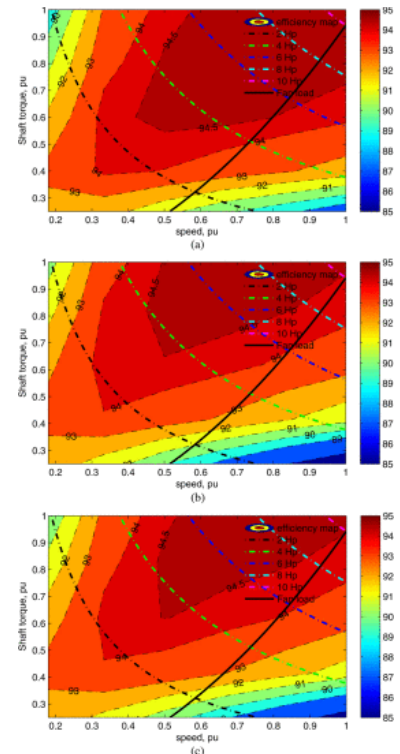

Fig. 7. Efficiency maps for three candidate optimum designs. (a) M-1; (b) M-2; (c) M-3.

Design M-3 was selected for prototyping and in serving as a performance reference, mainly due to the fact that it has the lowest cost, while still meeting the rated efficiency requirements, hence offering a good tradeoff between the two optimization objectives. The efficiency difference between M-3 and M1 provided in Fig. 8(a), indicates, that for fan/pump applications motor $\mathrm{M}-1$ can provide $0.3 \%$ to $0.8 \%$ higher efficiency than motor M-3. Nevertheless, design M-3 is superior for high torque low speed operation. The efficiency difference map from Fig. 8(b) shows that the M-3 motor has between $0 \%$ to $0.5 \%$ higher efficiency than the M-2 motor. 


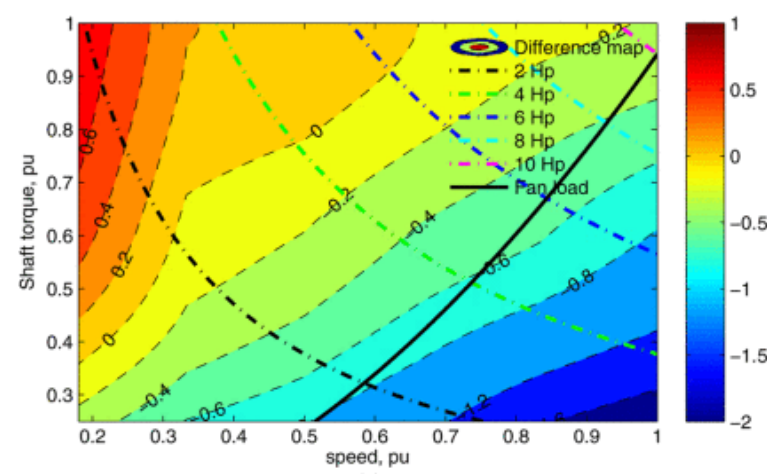

(a)

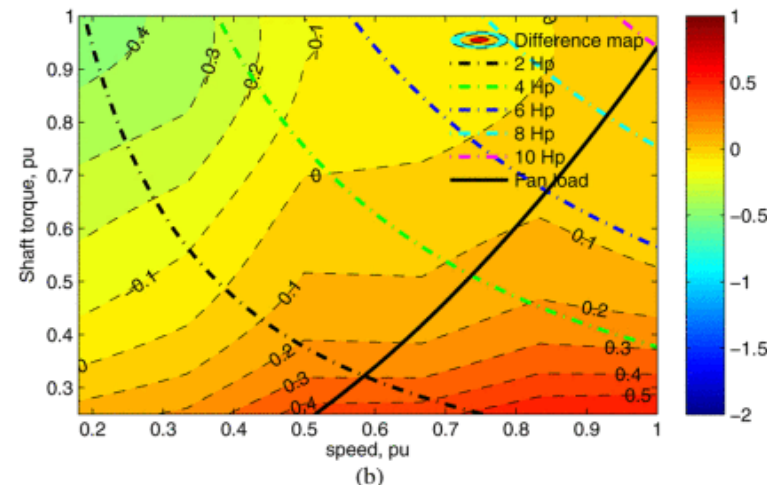

Fig. 8. Efficiency differences between three optimum candidate designs. (a) Efficiency difference between $M-3$ and $\mathrm{M}-1$; (b) Efficiency difference between $\mathrm{M}-3$ and $\mathrm{M}-2$.

\section{SECTION VI. Experimental Results and Calibration}

An IPM machine prototype based on the recommended M-3 design was built and tested on an active dyno set-up with a computer data acquisition system, as shown in Fig. 9. The IPM prototype was operated with a commercially available Yaskawa A1000, sensorless controlled sine-wave drive.

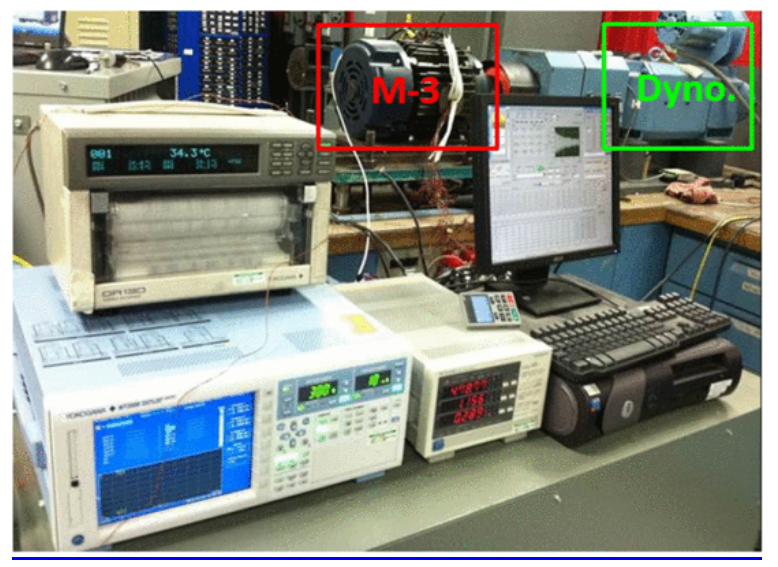

Fig. 9. Test dyno and data acquisition system for the 210-frame 10hp BLPM machine.

\section{A. Open Circuit Test}

Prior to the load measurements, an open circuit test was performed under "cold" temperature conditions at a winding temperature of $35^{\circ} \mathrm{C}$. The phase back-emf validation for open circuit operation 
at $1800 \mathrm{r} / \mathrm{min}$ provided in Fig. 10(a) confirms the satisfactory accuracy of the CE-FEA method for such simulations.
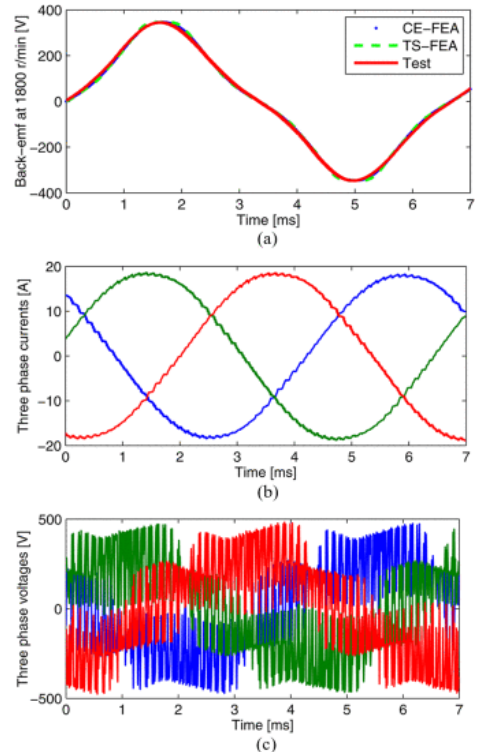

Fig. 10. Phase back-emf as well as three phase current and voltage waveforms at $1800 \mathrm{r} / \mathrm{min}$ under rated load condition.(a) Phase back-emf; (b) Phase currents; (c) Phase voltages.

\section{B. On-Load Tests}

A comprehensive on-load test for speeds from $600 \mathrm{r} / \mathrm{min}$ to $1800 \mathrm{r} / \mathrm{min}$ in increments of $300 \mathrm{r} / \mathrm{min}$ and for loads from $25 \%$ to $125 \%$ in increments of $25 \%$ of rated torque was performed. It should be noted that with the sensorless drive employed the user has limited control in accurately setting the torque angle, $\beta$, accordingly operation at exactly the predicted MTPA could not be ascertained. Instead, the rotor position was measured and this value together with the measured current value were employed in CE-FEA and TS-FEA calculations.

In line with expectations and with previous publications, e.g., [10], the results for the two aforementioned FEA techniques are in satisfactory agreement, while the CE-FEA method is one order of magnitude faster. Current and voltage waveforms measured under the rated load operation are shown in Fig. 10. A sample of computed and measured data is provided in Table IV.

TABLE IV Losses for Different Load and Speed Conditions. Here, $P_{C u}$ Is Calculated Based on the Measured dc Resistance, $P_{F e}$ and $P_{p m}$ Were Computed Using the TS-FEA, and $P_{f w}$ Is Estimated Based on a 10-hp Prototype IPM Machine

\begin{tabular}{|l|l|l|l|l|l|l|l|l|l|}
\hline & & & Computed & & & & & & \\
\hline Speed & Load & I & $P_{C u}$ & $P_{F e}$ & $P_{p m}$ & $P_{f w}$ & Total & Tested loss & Loss Diff. \\
\hline r/min & $\%$ & Arms & w & w & w & w & w & w & w \\
\hline \multirow{1}{1}{1800} & 25 & 3.3 & 11 & 97 & 3 & 91 & 200 & 219 & 19 \\
& 50 & 6.3 & 41 & 106 & 5 & 91 & 241 & 290 & 49 \\
& 75 & 9.4 & 90 & 112 & 9 & 91 & 297 & 383 & 86 \\
& 100 & 13.0 & 172 & 106 & 13 & 91 & 374 & 530 & 156 \\
& 125 & 17.6 & 319 & 102 & 20 & 91 & 518 & 807 & 289 \\
\hline
\end{tabular}




\begin{tabular}{|l|l|l|l|l|l|l|l|l|l|}
\hline 1500 & 25 & 3.2 & 10 & 71 & 2 & 69 & 152 & 174 & 23 \\
& 50 & 6.2 & 39 & 75 & 3 & 69 & 187 & 225 & 39 \\
& 75 & 9.2 & 88 & 82 & 6 & 69 & 244 & 324 & 83 \\
& 100 & 12.4 & 159 & 84 & 9 & 69 & 321 & 443 & 129 \\
& 125 & 15.8 & 257 & 88 & 13 & 69 & 428 & 614 & 197 \\
\hline 1200 & 25 & 3.2 & 11 & 48 & 1 & 49 & 109 & 138 & 29 \\
& 50 & 6.2 & 39 & 56 & 2 & 49 & 146 & 177 & 32 \\
& 75 & 9.2 & 87 & 63 & 4 & 49 & 203 & 260 & 61 \\
& 100 & 12.4 & 157 & 69 & 6 & 49 & 281 & 367 & 93 \\
& 125 & 15.7 & 253 & 70 & 8 & 49 & 382 & 517 & 146 \\
\hline 900 & 25 & 3.2 & 10 & 31 & 1 & 32 & 74 & 96 & 23 \\
& 50 & 6.2 & 40 & 33 & 1 & 32 & 106 & 144 & 40 \\
& 75 & 9.2 & 87 & 36 & 2 & 32 & 157 & 205 & 51 \\
& 100 & 12.4 & 157 & 39 & 3 & 32 & 232 & 305 & 80 \\
& 125 & 15.7 & 254 & 41 & 5 & 32 & 332 & 434 & 112 \\
\hline 600 & 25 & 3.1 & 10 & 17 & 0 & 17 & 45 & 65 & 20 \\
& 50 & 6.1 & 39 & 19 & 1 & 17 & 75 & 98 & 25 \\
& 75 & 9.1 & 85 & 20 & 1 & 17 & 124 & 155 & 35 \\
& 100 & 12.3 & 156 & 22 & 2 & 17 & 196 & 240 & 50 \\
& 125 & 15.7 & 252 & 23 & 2 & 17 & 294 & 351 & 67 \\
\hline
\end{tabular}

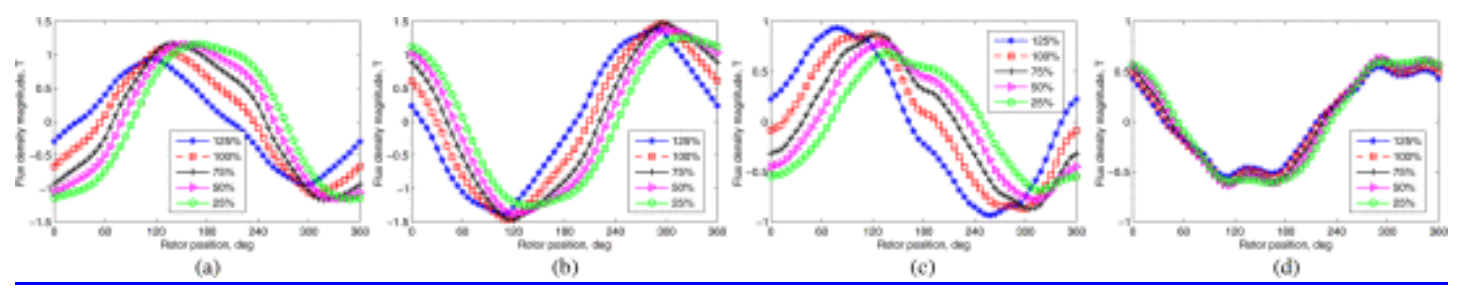

Fig. 11. Flux densities in the stator teeth and yoke [four points in Fig. 6(c)] at $1800 \mathrm{r} / \mathrm{min}$ under different load conditions. (a) Point 1 for tooth. (b) Point 2 for tooth. (c) Point 3 for yoke. (d) Point 4 for yoke. For position identification see Fig. 6.

\section{Discussion on Separation of Losses}

In Table IV, the copper losses were computed by multiplying the phase current squared with the dc resistance measured at the winding test temperature of $35^{\circ} \mathrm{C}$. The electromagnetic FEA considered sinewave currents and generic stranded conductor wires. Therefore, the ac ohmic losses were not modeled.

The calculated core losses and PM losses were computed by the 2-D (2-D) TS-FEA method. For the core loss calculation, the TS-FEA method utilized verified specific core loss coefficients $k_{h}$ and $k_{e}$, which were validated based on a set of open-circuit loss separation tests for a $10 \mathrm{hp}$ prototype PM machine. From such tests the friction and windage losses were measured separately, for which the PMs were not inserted into rotor laminations.

When the motor operates at the same speed, the flux density distributions in the stator core do not change significantly, which can be observed from the time-domain flux density waveforms in Fig. 11 for four distinct locations (center points of two adjacent stator teeth and yoke) in the stator core. These 
sampling points were provided in Fig. 6(c). In expression (11), the specific core loss only depends on the flux densities in the stator core and frequencies. Thus, when the PM machine operates at the same speed under various load conditions, the core losses do not vary significantly, which can be observed from the results in Table IV.

The tested losses provided in Table IV were equal to the difference between the measured input power and output power, which was calculated from the measured shaft torque. The differences between the estimated losses and tested losses are listed in the last column of Table IV. These loss differences, $P_{d i f}$, stem from the excess ac copper losses in the stator windings, which are caused by the skin and proximity effects from the fringing flux around the stator slots, e.g., [22]- [23] [24]. The linear dependency with the square of the phase current and the frequency at a power of 1.5

$$
P_{\text {dif }}=a_{1} I^{2}+b_{1}=a_{2} I^{2} f^{1.5}+b_{1}
$$

is illustrated in Fig. 12. Further research into the systematic separation of losses through detailed calculations and tests is currently being pursued and will be reported in a future paper.

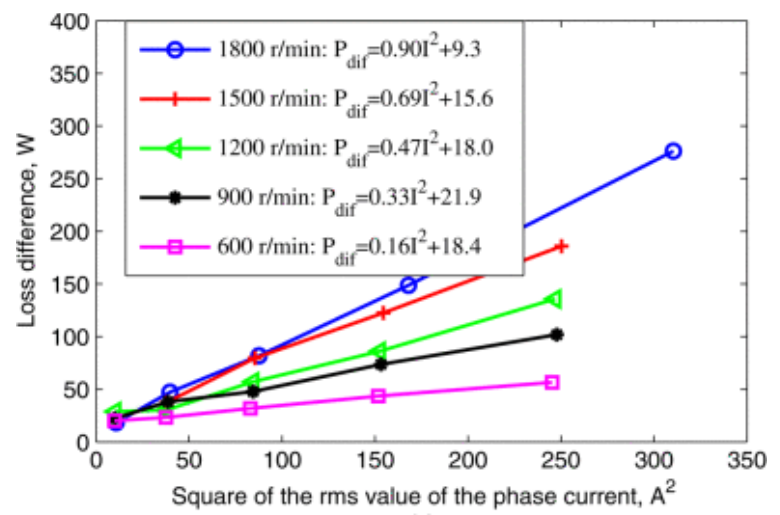

(a)

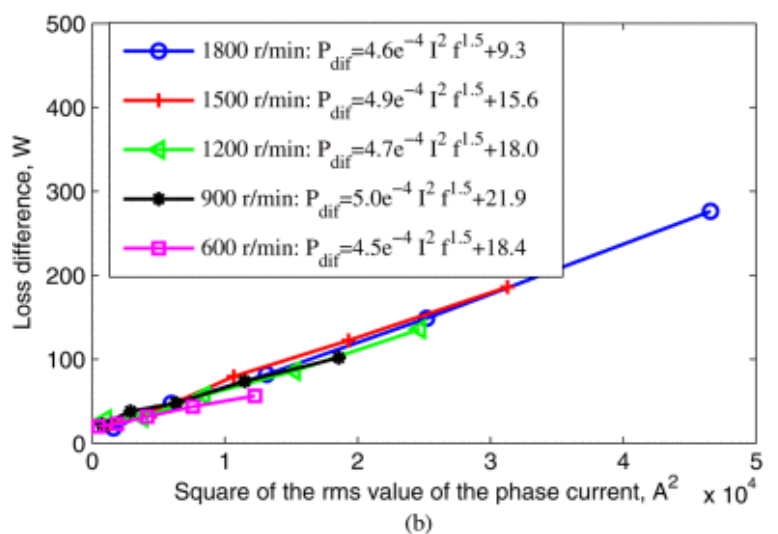

Fig. 12. Loss difference between the calculated results and test results, $P_{d i f}$, as function of the phase current and fundamental supply frequency. (a) $P_{\text {dif }}=a_{1} I^{2}+b_{1}$; (b) $P_{\text {dif }}=a_{2} I^{2} f^{1.5}+b_{1}$. 


\section{SECTION VII. Conclusion}

In this paper, a computationally efficient electromagnetic FEA (CE-FEA) technique, which calculates the waveforms of torque, torque ripple, induced voltage, and average losses, of current-regulated PM synchronous machines, was expanded and improved by implementing fast computation methods for motor nonlinear parameters, namely PM flux linkage, and dq-axes inductances. Using these parameters, a minimum-effort estimation of the torque angle delivering maximum torque per amp (MTPA) is possible and enables large scale optimization studies in an engineering design office environment.

A new design optimization scheme based on the extended CE-FEA method was implemented and demonstrated on a concentrated winding 12-slot 10-pole IPM case study rated at $10 \mathrm{hp}$. Based on a robust parametric model, nine independent variables were selected for a DE optimization with the concurrent objectives of minimizing losses and material cost with three constraints of torque ripple, THD of induced voltages and minimum operating point of PMs.

A total of 3,500 candidate designs were analyzed in 28 hours on a state of the art PC workstation, and automatically compared yielding a Pareto-set of recommended designs. The engineering analysis and discussion of tradeoffs between several candidate designs under variable speed and load operation included a newly proposed technique for plotting and subtracting efficiency maps over the torquespeed operating range. One design was prototyped, and successfully tested. The systematic analysis also pointed out some of the challenges specific to fractional-slot concentrated winding topologies in terms of increased stator winding and rotor core losses.

\section{References}

1. Y. Duan and D. M. Ionel, "A review of recent developments in electrical machine design optimization methods with a permanent magnet synchronous motor benchmark study", IEEE Trans. Ind. Appl., vol. 49, no. 3, pp. 1268-1275, May/Jun. 2013.

2. A. Arkadan, M. ElBsat and M. Mneimneh, "Particle swarm design optimization of ALA rotor SynRM for traction applications", IEEE Trans. Magn., vol. 45, no. 3, pp. 956-959, Mar. 2009.

3. F. Parasiliti, M. Villani, S. Lucidi and F. Rinaldi, "Finite-element-based multi-objective design optimization procedure of interior permanent magnet synchronous motors for wide constantpower region operation", IEEE Trans. Ind. Electron., vol. 59, no. 6, pp. 2503-2514, Jun. 2012.

4. W. Jiang, T. M. Jahns, T. A. Lipo, W. Taylor and Y. Suziki, "Machine design optimization based on finite element analysis in a high-throughput computing environment", Proc. IEEE ECCE, pp. 869876, Sep. 2012.

5. L. Jolly, M. Jabbar and L. Qinghua, "Optimization of the constant power speed range of a saturated permanent-magnet synchronous motor", IEEE Trans. Ind. Appl., vol. 42, no. 4, pp. 1024-1030, Jul./Aug. 2006.

6. M. Barcaro, N. Bianchi and F. Magnussen, "Permanent-magnet optimization in permanent-magnetassisted synchronous reluctance motor for a wide constant-power speed range", IEEE Trans. Ind. Electron., vol. 59, no. 6, pp. 2495-2502, Jun. 2012.

7. K. V. Price, R. M. Storn and J. A. Lampinen, Differential Evolution-A Practical Approach to Global Optimization, Berlin, Germany:Springer-Verlag, 2005. 
8. R. Ursem and P. Vadstrup, "Parameter identification of induction motors using differential evolution", Proc. CEC, vol. 2, pp. 790-796, 2003.

9. D. M. Ionel and M. M. Popescu, "Ultrafast finite-element analysis of brushless PM machines based on spacetime transformations", IEEE Trans. Ind. Appl., vol. 47, no. 2, pp. 744-753, Mar./Apr. 2011.

10. G. Y. Sizov, D. M. lonel and N. A. O. Demerdash, "Modeling and parametric design of permanentmagnet ac machines using computationally efficient-finite element analysis", IEEE Trans. Ind. Electron., vol. 59, no. 6, pp. 2403-2413, Jun. 2012.

11. G. Sizov, P. Zhang, D. lonel, N. Demerdash and M. Rosu, "Automated multi-objective design optimization of pm ac machines using computationally efficient- fea and differential evolution", IEEE Trans. Ind. Appl., vol. 49, no. 5, pp. 2086-2096, Sep./Oct. 2013.

12. P. Zhang, G. Sizov, J. He, D. M. lonel and N. Demerdash, "Calculation of magnet losses in concentrated-winding permanent magnet synchronous machines using a computationally efficient-Finite element method", IEEE Trans. Ind. Appl., vol. 49, no. 6, pp. 2524-2532, Nov./Dec. 2013.

13. G. Y. Sizov, P. Zhang, D. M. Ionel, N. A. O. Demerdash, I. P. Brown, A. O. Smith, et al., "Modeling and analysis of effects of skew on torque ripple and stator tooth forces in permanent magnet $A C$ machines", Proc. IEEE ECCE, pp. 3055-3061, 2012.

14. D. Ionel, M. Popescu, M. McGilp, T. Miller, S. Dellinger and R. Heideman, "Computation of core losses in electrical machines using improved models for laminated steel", IEEE Trans. Ind. Appl., vol. 43, no. 6, pp. 1554-1564, Nov./Dec. 2007.

15. M. Popescu, D. Ionel, A. Boglietti, A. Cavagnino, C. Cossar and M. McGilp, "A general model for estimating the laminated steel losses under PWM voltage supply", IEEE Trans. Ind. Appl., vol. 46, no. 4, pp. 1389-1396, Jul./Aug. 2010.

16. A. Boglietti, A. Cavagnino, D. Ionel, M. Popescu, D. Staton and S. Vaschetto, "A general model to predict the iron losses in PWM inverter-fed induction motors", IEEE Trans. Ind. Appl., vol. 46, no. 5, pp. 1882-1890, Sep./Oct. 2010.

17. ANSYS Maxwell.

18. D. Ionel, M. Popescu, C. Cossar, M. McGilp, A. Boglietti and A. Cavagnino, "A general model of the laminated steel losses in electric motors with PWM voltage supply", Proc. IEEE IAS Annu. Meet., pp. 1-7, 2008.

19. P. Zhang, G. Sizov, D. M. lonel and N. Demerdash, "Design optimization of spoke-type ferrite magnet machines by combined design of experiments and differential evolution algorithms", Proc. IEEE IEMDC, pp. 958-964, 2013.

20. N. Vaks, S. Sudhoff and S. Pekarek, "Investigation of tradeoffs between efficiency mass cost service factor and power factor in induction machines", SAE Int. J. Aerosp., vol. 3, no. 1, pp. 159-167, Dec. 2010.

21. Y. Duan and D. Ionel, "Non-linear scaling rules for brushless pm synchronous machines based on optimal design studies for a wide range of power ratings", Proc. IEEE ECCE, pp. 2334-2341, 2012.

22. C. Sullivan, "Computationally efficient winding loss calculation with multiple windings arbitrary waveforms and two-dimensional or three-dimensional field geometry", IEEE Trans. Power Electron., vol. 16, no. 1, pp. 142-150, Jan. 2001. 
23. S. Iwasaki, R. Deodhar, Y. Liu, A. Pride, Z. Zhu and J. Bremner, "Influence of PWM on the proximity loss in permanent-magnet brushless AC machines", IEEE Trans. Ind. Appl., vol. 45, no. 4, pp. 1359-1367, Jul./Aug. 2009.

24. M. Popescu and D. G. Dorrell, "Skin effect and proximity losses in high speed brushless permanent magnet motors", Proc. IEEE ECCE, pp. 3521-3527, 2013. 